\title{
Silent Cerebral Infarctions in Type II Diabetes Mellitus Patients; Could Brain MRI Be a Routine Investigation?
}

\author{
Mohamed Hamdy Ibrahim1, Taha Kamel Alloush', Marwa Adel Shaaban², \\ Mohammed Khalid Abdul Rahim ${ }^{3}$, Mohammad Ahmad M. Saad ${ }^{4}$ \\ ${ }^{1}$ Neurology Department, Faculty of medicine, Ain shams University, Cairo, Egypt \\ ${ }^{2}$ Radiology Department, Misr University for Science and Technology, Cairo, Egypt \\ ${ }^{3}$ Internal Medicine Department, Gulf Medical University, Ajman, UAE \\ ${ }^{4}$ Radiology Department, Fayoom University, Fayoom, Egypt \\ Email: mohamedhamdy neuro2007@yahoo.com
}

Received 18 June 2014; revised 18 July 2014; accepted 15 August 2014

Copyright (C) 2014 by authors and Scientific Research Publishing Inc.

This work is licensed under the Creative Commons Attribution International License (CC BY). http://creativecommons.org/licenses/by/4.0/

c) (i) Open Access

\begin{abstract}
Objective: To study the prevalence of silent cerebral infarction in Type II diabetes mellitus. Patients and Methods: The study was a prospective on 80 patients recruited from neurology, endocrine outpatient clinics. Patients were type II diabetics as described by the American Diabetes Association, 2011 criteria. All patients underwent full metabolic profiles to diagnose diabetes mellitus and MRI brain scans to detect cerebral infarction. Results: Silent cerebral infarctions were detected in $60 \%$ of patients $(48 / 80$ patients) predominately along periventricular white matter area and subcortical areas (Basal ganglia, Thalamus). Conclusion: Asymptomatic Type II diabetes mellitus patients could have vascular cerebral changes without neurological symptoms. MRI brain scans could be recommended as routine diagnosis (if possible) for early cerebral infarct detection in type II diabetic patients.
\end{abstract}

\section{Keywords}

Prevalence, Silent Brain Infarction, Diabetes Mellitus

\section{Introduction}

Diabetes mellitus type 2 (formerly noninsulin-dependent diabetes mellitus (NIDDM) or adult-onset diabetes) is a metabolic disorder that is characterized by hyperglycemia (high blood sugar) in the context of insulin resis- 
tance and relative lack of insulin [1]. The diagnosis is in contrast to diabetes mellitus type 1, in which there is an absolute lack of insulin due to breakdown of islet cells in the pancreas [2]. The classic symptoms are excess thirst, frequent urination, and constant hunger. Type 2 diabetes makes up about $90 \%$ of cases of diabetes [3].

With the advent of highly sensitive techniques for brain imaging such as MRI, a wide range of potentially abnormal findings has been reported and noted to increase in frequency with age [4]. Such findings include lesions with an appearance typical of infarction; when these appear in persons without a history compatible with stroke, they are often referred to as "silent infarcts". The strong relationship of these findings with age and other stroke risk factors suggests that they themselves may be risk factors or even manifestations of clinically important cerebrovascular disease [5].

Silent cerebral infarctions (SCIs), also termed covert infarcts or simply MRI infarcts, are parenchymal lesions that have the MRI characteristics of previous infarcts but have not been associated in that individual with clinical signs or symptoms corresponding to a stroke. They were first described by Fisher [6] in a cohort of 114 subjects who came to autopsy; 88 brains had at least 1 lacune in the absence of clinical deficits or a stroke history. In recent studies, the prevalence of SCI on MRI scans has ranged from $5.84 \%$ to $28 \%$. Reasons for this variation in prevalence may include differences in the definition of SCI, in MRI techniques, age, sex, and risk factor profile of the population being studied [1] [2].

\section{Patients and Methods}

The prospective study was conducted from April 2013 to December 2013 on 80 patients from neurology, endocrine and internal medicine outpatient clinics. Patients were informed about research objectives and benefits. Written consents were obtained and signed and approved by the local ethnic committee.

Inclusion criteria: Age: 20 - 65 years. Males and females were included. The inclusion criteria for diabetes mellitus: any patient who was a known diabetic on medication.

Criteria for diagnosis of Diabetes mellitus [6] (type II):

- Symptoms of diabetes plus random blood glucose concentration $>200 \mathrm{mg} / \mathrm{dl}$ or

- Fasting plasma glucose $>126 \mathrm{mg} / \mathrm{dl}$ or

- $\mathrm{HbA} 1 \mathrm{C}>6.5 \%$ or

- Two hour plasma glucose $>200 \mathrm{mg} / \mathrm{dl}$ during an oral glucose tolerance test

Exclusion criteria: includes, previous stroke, any other metabolic conditions to be excluded (i.e. Diabetes complicated by renal failure).

\section{Image Acquisition}

All imaging studies were performed on Siemens MRI-scanner MAGNETOM Aera, 1.5 Tesla T1 and T2-weighted FSE images with 5 mm thick sections, $256 \times 256$ matrix, FOV 20 cm, TR 5650, TE 102, and 16 echo train length.

The MRI examinations included FLAIR, T2- and T1-weighted spin-echo images with 5-mm thickness and zero gap and oriented parallel to the anterior-posterior commissure line.

Infarcts by MRI were defined as lesions with abnormal signal in a vascular distribution and no mass effect. Infarcts of the cortical gray matter and deep nuclear regions and capsule were defined as lesions bright on FLAIR and T2-weighted images compared with normal gray matter and isodense or hypodense on T1-weighted images. Infarcts in the white matter were also bright on spin-density and T2-weighted images but in addition were hypointense on T1-weighted images [5].

Demographic: With regards to gender, 60 patients (75\%) were male and 20 patients (25\%) were female. The mean group age was 42.4 years. Criteria and distribution of MRI brain lesions are described in Table 1, Figure 1, Figure 2 and Figure 3.

From the table we noticed that $50 \%$ of cases (24/48) had silent cerebral infarctions with periventricular white matter distribution, 33.3\% (16/48) had infarcts in the basal ganglia and 16.66\% had infarction in the thalamus.

Table 1. Site and distribution of silent cerebral infarction detected by MRI brain.

\begin{tabular}{cl}
\hline Number of cases with Positive MRI brain findings & \multicolumn{1}{c}{ Site of silent cerebral infarction detected by MRI brain } \\
& 24 cases periventricular white matter \\
48 cases have positive findings (60\%) & 16 cases basal ganglia \\
& 8 cases Thalamus \\
\hline
\end{tabular}




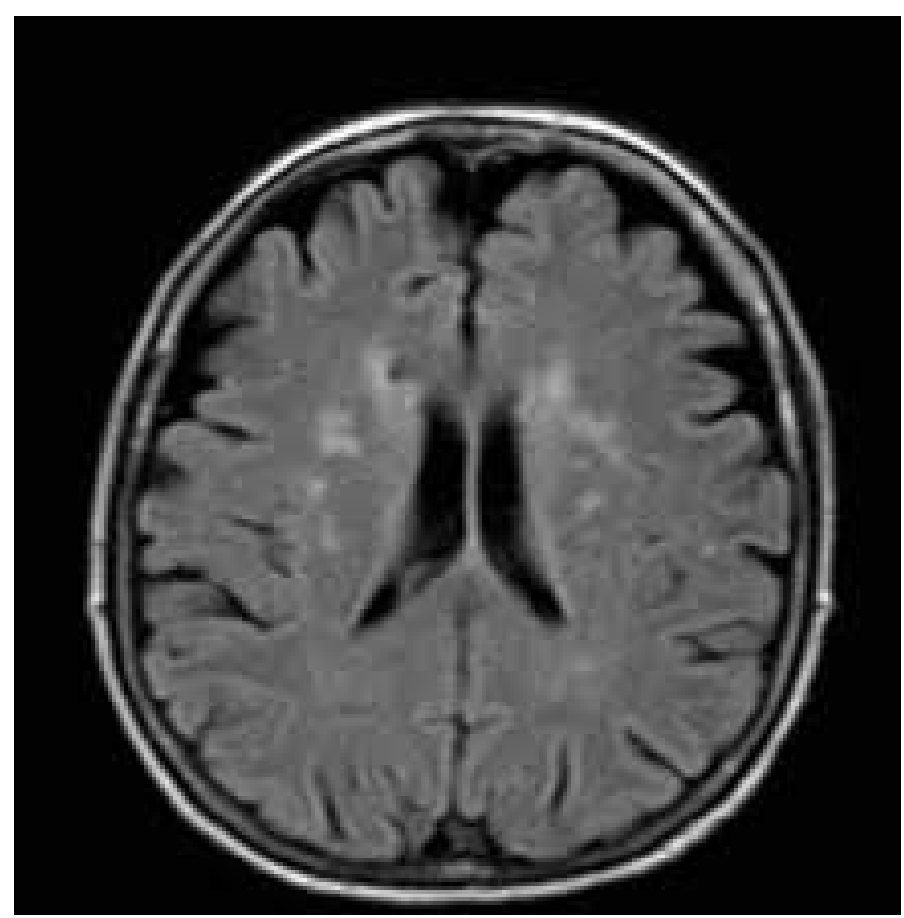

Figure 1. A 51-year-old male patient with multiple periventricular lacunar infarctions of high FLAIR signal.

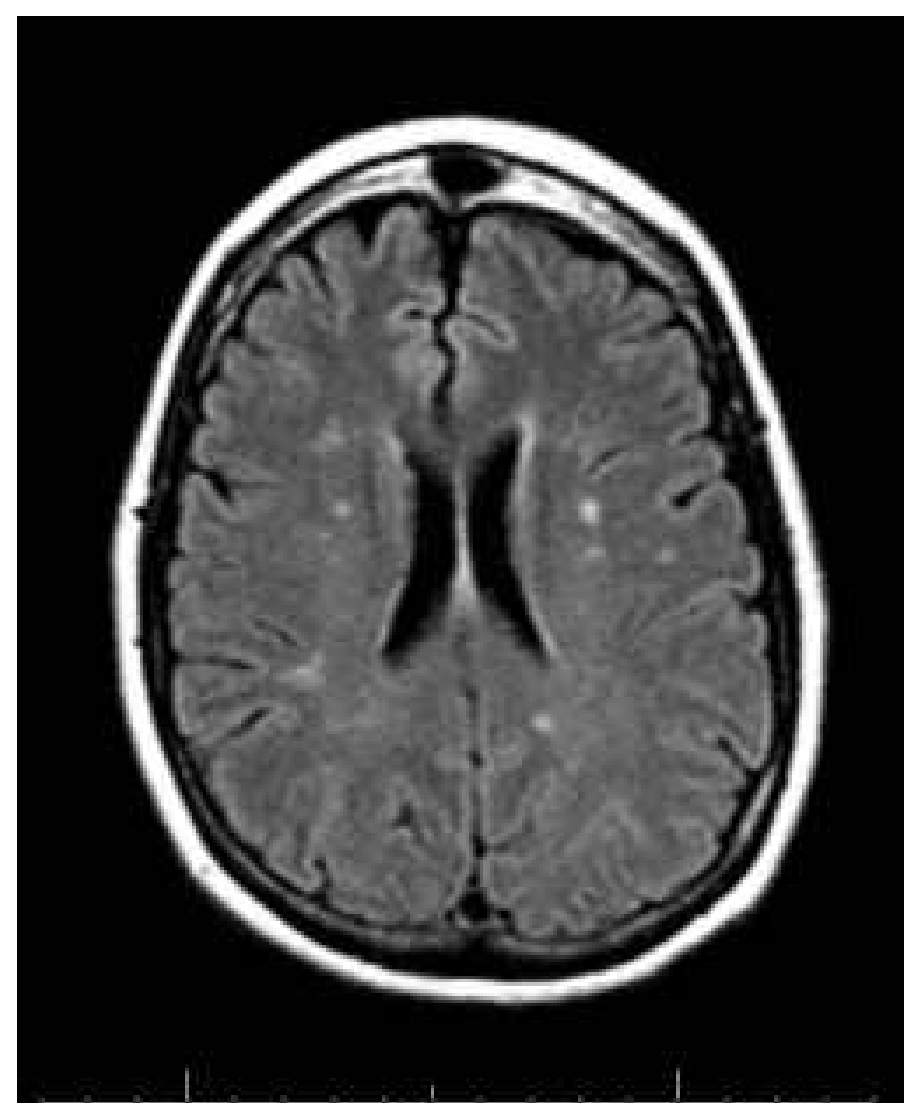

Figure 2. A 63-year-old male patient with multiple head of caudate and posterior periventricular infarctions of high FLAIR signal. 


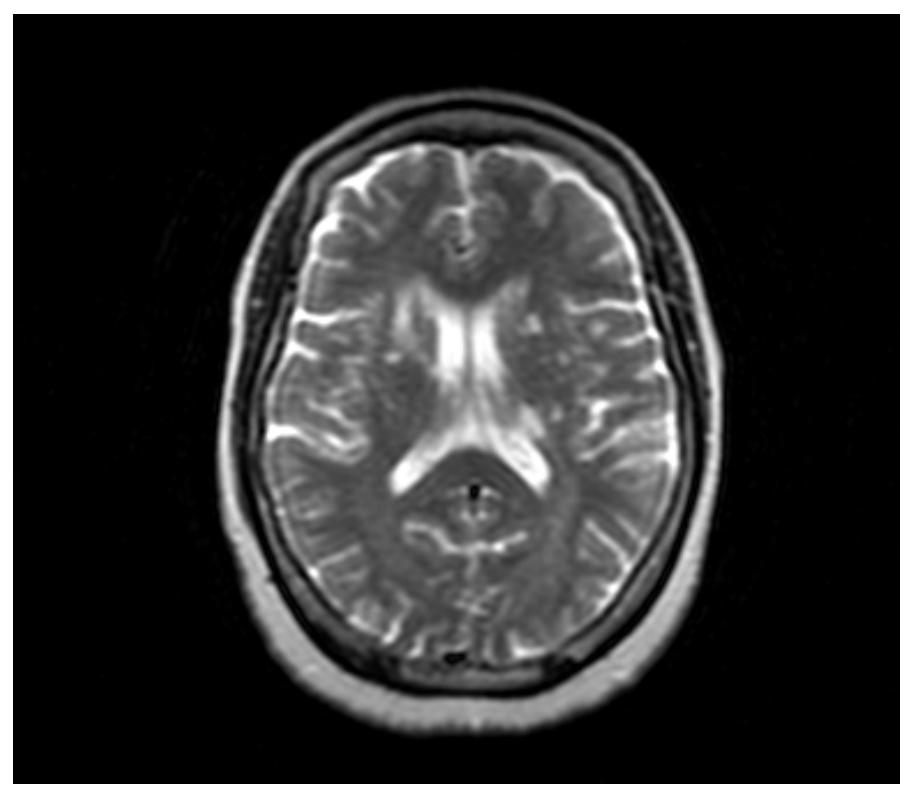

Figure 3. A 61-year-old female A 61 bilateral basal ganglia foci of CSF signal and anterior limb of the right internal capsule and adjacent part of caudate nucleus lesion of high T2 signal.

\section{Discussion}

Silent cerebral infarction (SCI) is a disruption in the flow of blood to the brain (stroke) that produces symptoms so brief and mild that the person often does not become concerned or seek medical attention. The SCI is found by chance when the patient is examined by MRI (magnetic resonance imaging), often for an unrelated condition.

MRI has the advantage of lack of exposure to ionizing radiation but the disadvantage of higher cost. While the availability of MRI is increasing, there are many acute care centers that continue to lack access to an on-site 24-hour-a-day MRI. There are also absolute and relative contraindications to MRI, limiting its availability, such as cardiac pacemakers and certain metallic implanted substances. Claustrophobia is more common with MRI than with CT. However, with faster scanning time and continuing improvement in short bore and open MRI technology, claustrophobia is a decreasing concern [7].

While numerous reports have documented the frequency of presumed infarctions on CT or MRI in persons with a history of (or at risk for) overt stroke [8]-[12], few studies have reported prevalence of such lesions in an asymptomatic community-dwelling population [13].

The American Heart Association reports that the finding of a SCI is a warning that the patient may develop a more serious stroke. The significance of this research is to increase awareness of treating physicians about SCI to aware health decision makers about this health problem and to highlight the extension of this problem in community at large population [14] [15].

Results of our study showed that $60 \%$ of our sample had positive MRI findings at T1 and T2 and FLAIR suggestive of cerebral ischemia in asymptomatic patients with diabetes mellitus type II. This differs from the results obtained by Nakamura and his colleague [16] who found that $20 \%$ had silent cerebral infarction. This difference could be due to differences in study design, sample size or the degree of disease progression before the MRI brain scan was conducted.

In our study we found that the lesions had certain distribution as $50 \%$ are mainly periventricular, $33.3 \%$ at basal ganglia and $16.66 \%$ at thalamus. This may explain that perforator vessels are more affected than the other cerebral vessels.

The findings suggested a relation between gender of the patient and MRI brain lesion distribution. Because it was not included in our study design we were unable to support this interpretation. Future studies should study such a relationship, if possible.

We recommend the use of MRI brain as a routine investigation in neurologically asymptomatic diabetic patients to detect early vascular ischemic changes. 


\section{Limitations}

Our study was limited by the relatively low patient number due to refusal of some diabetic patients to participate in the study.

\section{Recommendations}

Prospective, large population studies should be conducted to detect any relationship between gender of the patient and silent cerebral infarction lesions distribution.

\section{References}

[1] Price, T.R., Manolio, T.A., Kronmal, R.A., Kittner, S.J., Yue, N.C., Robbins, J., Anton-Culver, H. and O’Leary, D.H. (1997) Silent Brain Infarction on Magnetic Resonance Imaging and Neurological Abnormalities in Community-Dwelling Older Adults. The Cardiovascular Health Study. Stroke, 28, 1158-1164. http://dx.doi.org/10.1161/01.STR.28.6.1158

[2] Fisher, C.M. (1965) Lacunes: Small, Deep Cerebral Infarcts. Neurology, 15, 774-784. http://dx.doi.org/10.1212/WNL.15.8.774

[3] American Diabetes Association (2010) Diagnosis and Classification of Diabetes Mellitus. Diabetes Care, 33, S62-S69. http://dx.doi.org/10.2337/dc10-S062

[4] Brant-Zawadzki, M., Fein, G., Van Dyke, C., Keirman, R., Davenport, L. and De Groot, J. (1985) MR Imaging of the Aging Brain. American Journal of Neuroradiology, 6, 675-682.

[5] Price, T.R., Manolio, T.A., Kronmal, R.A., Kittner, S.J., Yue, N.C., Robbins, J., Anton-Culver, H. and O’Leary, D.H. (1997) Silent Brain Infarction on Magnetic Resonance Imaging and Neurological Abnormalities in Community-Dwelling Older Adults. Stroke, 28, 1158-1164. http://dx.doi.org/10.1161/01.STR.28.6.1158

[6] Ezekowitz, M.D., James, K.E., Nazarian, S.M., Davenport, J., Broderick, J.P., Gupta, S.R., Thadani, V., Meyer, M.L. and Bridgers, S.L. (1995) Silent Cerebral Infarction in Patients with Nonrheumatic Atrial Fibrillation. The Veterans Affairs Stroke Prevention in Nonrheumatic Atrial Fibrillation Investigators. Circulation, 92, 2178-2182. http://dx.doi.org/10.1161/01.CIR.92.8.2178

[7] Xavier, A.R., Qureshi, A.I., Kirmani, J.F., Yahia, A.M. and Bakshi, R. (2003) Neuroimaging of Stroke: A Review. Southern Medical Journal, 96, 367-379.

[8] Kase, C.S., Wolf, P.A., Chodosh, E.H., Zacher, H.B., Kelly-Hayes, M., Kannel, W.B., D’Agostino, R.B. and Scampini, L. (1989) Prevalence of Silent Stroke in Patients Presenting with Initial Stroke: The Framingham Study. Stroke, 20, 850-852. http://dx.doi.org/10.1161/01.STR.20.7.850

[9] Davis, P.H., Clarke, W.F., Bendixen, B.H., Culebras, A., Adams, H.P. and Woolson, R.F. (1994) Silent Stroke in Patients Enrolled in the TOAST Study. Neurology, 44, A225.

[10] Chodosh, E.H., Foulkes, M.A., Kase, C.S., Wolf, P.A., Mohr, J.P., Hier, D.B., Price, T.R. and Furtado, J.G. (1988) Silent Stroke in the NINCDS Stroke Data Bank. Neurology, 38, 1674-1679. http://dx.doi.org/10.1212/WNL.38.11.1674

[11] Jorgensen, H.S., Nakayama, H., Raaschou, H.O., Gam, J. and Olsen, T.S. (1994) Silent Infarction in Acute Stroke Patients: Prevalence, Localization, Risk Factors and Clinical Significance: The Copenhagen Stroke Study. Stroke, 25, 97104. http://dx.doi.org/10.1161/01.STR.25.1.97

[12] Herderschee, D., Hidra, A., Algna, A., Koudstaal, P.J., Kappelle, L.J. and Van Gijn, J. (1992) Silent Stroke in Patients with Transient ischemic Attack or Minor Ischemic Stroke. Stroke, 23, 1220-1226. http://dx.doi.org/10.1161/01.STR.23.9.1220

[13] Bryan, R.N., Wells, S.W., Miller, T.J., Elster, A., Jungreis, C., Poirier, V., Lind, B. and Manolio, T.A. (1997) Prevalence and Anatomic Characteristics of Infarct-Like Lesions on MRI in the Elderly: Data from the Cardiovascular Health Study (CHS). Radiology, 202, 47-54. http://dx.doi.org/10.1148/radiology.202.1.8988191

[14] Kumar, V., Fausto, N., Abbas, A.K., Cotran, R.S. and Robbins, S.L. (2005) Robbins and Cotran Pathologic Basis of Disease. 7th Edition, Saunders, Philadelphia, 1194-1195.

[15] Gardner, D. and Shoback, D. (2011) Greenspan’s Basic \& Clinical Endocrinology. 7th Edition, McGraw-Hill Medical, New York, Chapter 17.

[16] Nakamura, T., Kawagoe, Y., Matsuda, T., Ueda, Y., Ebihara, I. and Koide, H. (2005) Silent Cerebral Infarction in Patients with Type 2 Diabetic Nephropathy. Effects of Antiplatelet Drug Dilazepdihydrochloride. Diabetes/Metabolism Research and Reviews, 21, 39-43. http://dx.doi.org/10.1002/dmrr.473 
Scientific Research Publishing (SCIRP) is one of the largest Open Access journal publishers. It is currently publishing more than 200 open access, online, peer-reviewed journals covering a wide range of academic disciplines. SCIRP serves the worldwide academic communities and contributes to the progress and application of science with its publication.

Other selected journals from SCIRP are listed as below. Submit your manuscript to us via either submit@scirp.org or Online Submission Portal.
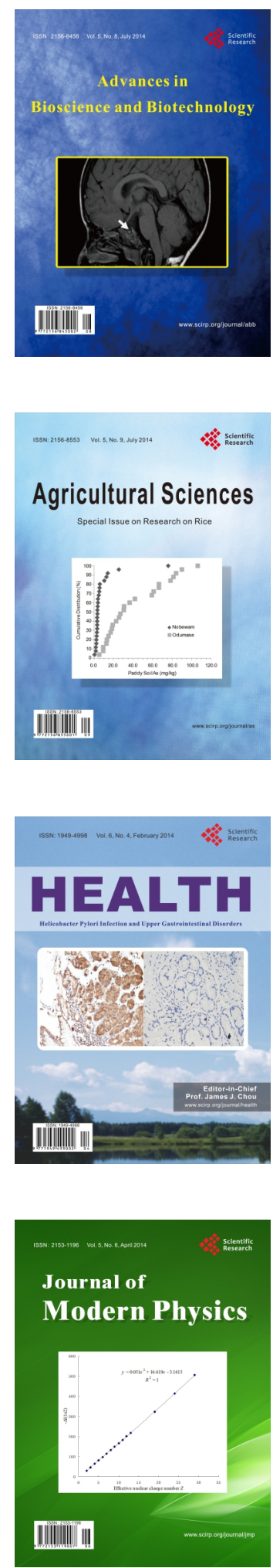
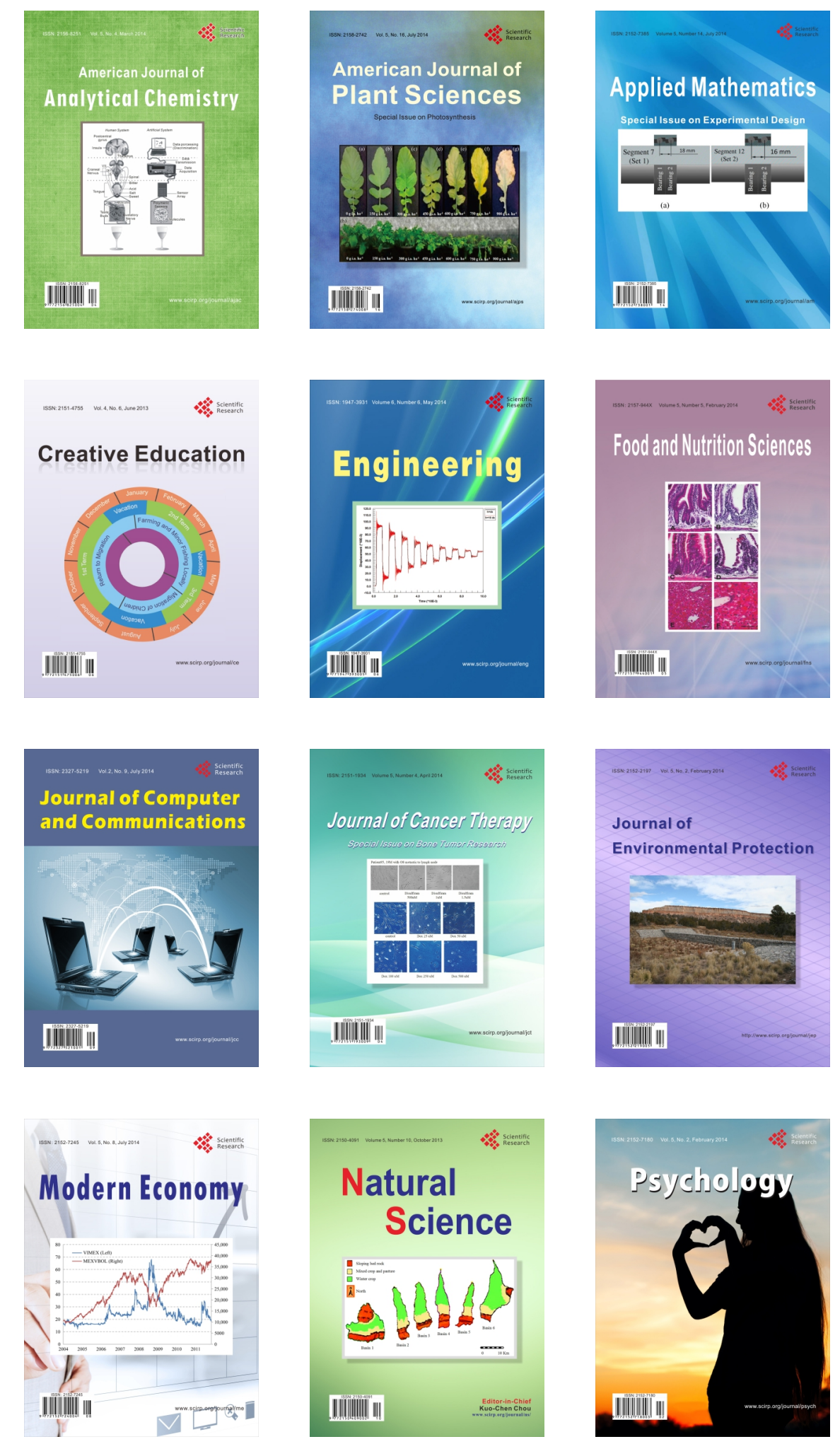